\title{
The effect of past experience on the size of shells selected by hermit crabs
}

\author{
BRIAN A. HAZLETT \\ Department of Biology, University of Michigan, Ann Arbor, MI 48109, U.S.A.
}

(Received 18 June 1991; initial acceptance 20 July 1991; final acceptance 19 September 1991; MS. number: 16080 )

\begin{abstract}
The relationship between crab size and shell size selected, in a free-choice situation, was tested for crabs maintained under several conditions. Individuals of Calcinus tibicen that were held and presented with an excess of shells for 7 days prior to testing selected smaller shells than control crabs (either those maintained for 7 days with no excess shells available or those experiencing natural field conditions). This shift occurred whether the excess shell type was the same or different from the shell type tested after experience. In a similar set of experiments, individuals of $C$. laevimanus were held for 31 days and although the trends in shell choice were similar to those for $C$. tibicen, the differences were not significant.
\end{abstract}

Hermit crabs often use an empty gastropod snail shell to protect their soft abdomen. The size and species of shells occupied has numerous ramifications for the biology of hermit crabs, including growth, survivorship and reproductive potential (Hazlett 1981, 1989; Borjesson \& Szelistowski 1989; Wilber 1989). Because empty gastropod shells are not usually abundant in the intertidal zone (Hazlett 1981), hermit crabs are exposed to varying degrees of resource availability in terms of shell choice. Occupying a shell that is too large could negatively effect growth and fecundity of the crab and its ability to protect itself from predators (Vance 1972; Bertness 1981). However, given the low probability of finding the right size of empty shell, following an increase in size via growth by a crab, crabs may accept or even select a shell that is slightly too large if it becomes available (Childress 1972). The discrepancy in shell size selected should be a function of the crab's recent experience with resource availability. Therefore, crabs should modify their preference for shell size based on the availability of empty shells.

In the following experiments, I address the question of how short-term exposure to differing shell resource levels influences the size of shell selected by hermit crabs. In particular, do crabs select smaller shells if environmental cues indicate an excess of this resource? And does this environmental influence work across shell species?

\section{METHODS}

I conducted observations on the behaviour of Calcinus laevimanus at Coconut Island, Oahu. Hawaii, in 1988 and on Calcinus tibicen (shipped from the Florida Keys) at Ann Arbor, Michigan, in 1990 and 1991. The general procedure for both species for each replicate was to provide 30 individuals free access to 200 shells of a given species for $24 \mathrm{~h}$ (see Wilber 1990) after the crabs had been in one of four prior conditions. These conditions were: (1) recently collected in the field, (2) held in the laboratory in an aquarium with no excess shells available for either 7 (C. tibicen) or 31 (C. laevimanus) days, (3) held in the laboratory in an aquarium with excess shells of the shell species to be tested for 7 or 31 days, or (4) held in the laboratory in an aquarium with excess shells of a different species of gastropod for 7 or 31 days. Calcinus laevimanus was tested with Trochus intexus and Turbo sanwichensis; $C$. tibicen was tested with Nerita sp. and Cerithium sp. shells.

After crabs had been in the free-access situation for $24 \mathrm{~h}$, I removed them and measured several parameters. I measured cephalothorax length and allowed the shells to dry for 2-4 days, at which time shell weight and internal volume were determined. Shell volume was determined by weighing the shell before and after fine dry sand was added to the dry shell. Knowing the density of the sand I was able to calculate the internal volume of the shell. The data were analysed using an analysis of covariance (ANCOVA). A significant interaction between 
Table I. Simple regression between crab size and internal volume of Turbo shells chosen by individuals of C. laevimanus under three conditions

\begin{tabular}{llrl}
\hline Condition & Regression & $r^{2}$ & $N$ \\
\hline
\end{tabular}

Field condition $\quad$ vol $=0.26$ (crabsize) $-1.20 \quad 0.525 \quad 24$

Excess Turbo $\quad$ vol $=0.39$ (crabsize) $-2.28 \quad 0.72423$

$\begin{array}{llll}\text { Excess Trochus } \quad \text { vol }=0.32 \text { (crabsize) }-1.68 & 0.664 & 27\end{array}$

prior condition and crab size in explaining variance in the volume of shells chosen would indicate that prior condition does affect the relationship between crab size and shell size chosen.

\section{RESULTS}

While there was the usual strong correlation between crab size and shell size chosen for $C$. laevimanus $(F=103.0, P<0.0001)$, there were no significant differences between the different conditions for the crab size and shell size chosen relationship (ANCOVA interaction term, $F=1.5$, $P=0 \cdot 228$ ). There was a suggestion that the slopes were more similar for the two excess-shells conditions than they were to the slope for the field condition animals (Table I), but this was not statistically significant.

The experiments with C. tibicen involved replicates with either Nerita sp. or Cerithium sp. as the shell type tested. In all cases, there was a strong relationship between crab size and shell size chosen and a significant interaction term between prior condition and crab size in explaining variance in volume of shells chosen. This is illustrated in Fig. 1 for the replicates which involved excess shells of the shell species being chosen. For these, the interaction term indicating an effect of prior condition on the regression between crab and shell sizes was significant both when the crabs were selecting from Nerita $(F=15.0, P=0.0001)$ and when selecting from Cerithium shells $(F=5 \cdot 8, P=0.004)$ (Table II).

The second set of experiments involving $C$. tibicen included replicates of the conditions used in the above experiments, and in addition, included tests with excess shells of other species as another condition. Some $C$. tibicen were held with excess Cerithium for 7 days and then given a choice among excess empty Nerita shells; others were held with excess Nerita shells for 7 days and then given a choice among excess empty Cerithium shells. Thus, for each species of shell being tested with the crabs, there were three test conditions: (1) held for 7 days while occupying the focal species of shell with no excess shells, (2) held for 7 days with excess of the focal species of shell, and (3) held for 7 days with excess of the other species of shell. The data were analysed for both a prior condition effect (excess, no excess) and a prior species effect (focal species, other species).

When choosing from Nerita shells, there was a prior condition effect $(P=0 \cdot 05)$ but no effect of prior species $(P=0.46)$ or of a prior condition $\times$ prior species interaction term $(P=0 \cdot 26)$. This means that having excess shells available altered the sizes chosen but it did not matter what species of shells were present in excess. When choosing among Cerithium shells, there was no prior condition effect $(P=0.732)$ but there was both a prior species effect $(P=0.02)$ and a prior condition $\times$ prior species interaction $(P=0 \cdot 04)$. The latter suggests that condition did have an effect but it differed depending upon the species of shell (Table II).

\section{DISCUSSION}

The results of the experiments reported here indicate that hermit crabs will modify the size of shell they choose based on their recent experience with shell availability. This was true for individuals of C. tibicen even when the excess shells were of a different species to those being selected. It would appear that crabs that have experience with a surplus of empty shells, choose a shell that may be closer to the optimal size than crabs that experience no excess of resources.

The regression lines for both Nerita and Cerithium suggest that this change in shell size selection, affected by recent experience, is strongest for smaller crabs. The larger crabs (more experienced with shell limitation in the field) did not select smaller shells after 1 week of experience with excess shells. This tendency suggests both short-term and longer-term experience effects. Because of their experiences in the field where large shells are in particularly short supply (Vance 1972), larger crabs would not be as readily influenced by a 1 -week experience in the laboratory.

The lack of a significant effect in the case of $C$. laevimanus could be due to several differences in methodology or to a species difference. Animals were held in the laboratory for 4 weeks rather than 1 week. In addition, a disproportionate number of 


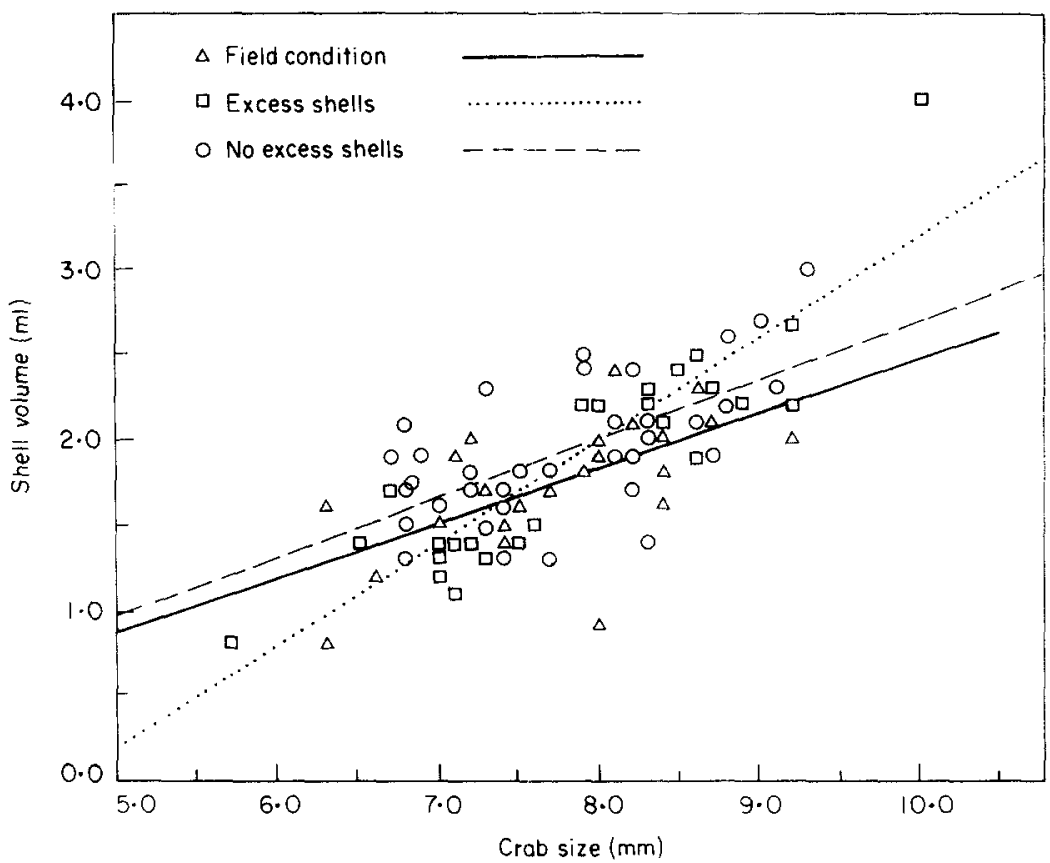

Figure 1. The relationship between crab size (cephalothorax length) and Cerithium shell size (internal volume) selected by individuals of $C$. tibicen held under different conditions prior to testing.

Table II. Results of ANCOVA on shell volume chosen by individual $C$. tibicen held under one of four conditions (see text for details)

\begin{tabular}{|c|c|c|c|c|}
\hline \multirow[b]{2}{*}{ Factor } & \multicolumn{2}{|c|}{$\begin{array}{l}\text { Cerithium sp. } \\
\quad(N=96)\end{array}$} & \multicolumn{2}{|c|}{$\begin{array}{l}\text { Nerita sp. } \\
(N=57)\end{array}$} \\
\hline & $F$ & $P$ & $F$ & $P$ \\
\hline Crabsize & $108 \cdot 5$ & $0 \cdot 000$ & $178 \cdot 7$ & 0.000 \\
\hline Prior condition* & $5 \cdot 7$ & 0.004 & $12 \cdot 7$ & 0.001 \\
\hline Crabsize $\times$ condition & $5 \cdot 8$ & 0.004 & $15 \cdot 0$ & $0 \cdot 000$ \\
\hline
\end{tabular}

*These data involved just those replicates with excess shells of the same species as that being selected.

larger C. laevimanus were used in those experiments compared with the test with $C$. tibicen, thus the individuals most readily affected by recent experience may not have been tested.

\section{ACKNOWLEDGMENTS}

I wish to thank the staff at the Hawaii Institute of Marine Biology for their assistance and Catherine Bach for her comments on the manuscript.

\section{REFERENCES}

Bertness, M. 1981. The influence of shell-type on hermit crab growth rate and clutch size (Decapoda, Anomura). Crustaceana, 40, 197-205.

Borjesson, D. L. \& Szelistowski, W. A. 1989. Shell selection, utilization and predation in the hermit crab Clibanarius panamensis Stimpson in a tropical mangrove estuary. J. exp. Mar. Biol. Ecol.. 133, 213-228.

Childress, J. R. 1972. Behavioral ecology and fitness theory in a tropical hermit crabs. Ecology, 53, 960-964.

Hazlett, B. A. 1981. The behavioral ecology of hermit crabs. A, Rev. Ecol. Syst., 12, 122.

Hazlett, B. A. 1989. Mating success of male hermit crabs in shell generalist and shell specialist species. Behav. Ecol. Sociobiol., 25, 119-128.

Vance, R. R. 1972. The role of shell adequacy in behavior interactions involving hermit crabs. Ecologv. 53, $1075-1083$.

Wilber, T. P., Jr. 1989. Associations between gastropod shell characteristics and egg production in the hermit crab Pagurus longicarpus. Oecologia (Berl.), 81, 6-15.

Wilber, T. P., Jr. 1990. Influence of size. species and damage on shell selection by the hermit crab Pagurus longicarpus. Mar. Biol., 104, 31 39. 